\title{
A terminologia do domínio do ciclismo no Brasil: casos de variação entre os termos que denominam as partes principais da bicicleta de estrada
}

DOI: http://dx.doi.org/10.21165/el.v49i2.2569

\author{
Milena de Paula Molinari' \\ Maurizio Babini²
}

\section{Resumo}

O objetivo principal deste trabalho consiste em analisar a terminologia do domínio do ciclismo de estrada veiculada por manuais desse tipo de veículo difundidos no Brasil, refletindo, especificamente, sobre as variantes dos termos denominativos das partes principais da bicicleta de estrada encontradas nesse tipo de documento. Para tanto, adotamos os princípios teóricos e metodológicos da Teoria Comunicativa da Terminologia (CABRÉ, 1999) e também nos baseamos nos critérios propostos por Faulstich (1997, 2001) para estabelecer as variantes terminológicas. Dentre os principais resultados obtidos, destacamos a presença de 7 casos de variantes lexicais e 22 de variantes geográficas. Com base nesses dados, verificamos que muitos manuais divulgados no Brasil por empresas europeias foram traduzidos para o português de Portugal, o que nos levou a encontrar um grande número de variantes geográficas em nossas análises, uma vez que partimos do português do Brasil. Com este estudo, esperamos, então, que possamos contribuir com uma melhor comunicação nessa área, sobretudo, no contexto brasileiro.

Palavras-chave: Terminologia; variação terminológica; ciclismo de estrada.

\footnotetext{
1 Universidade Estadual Paulista "Júlio de Mesquita Filho" (UNESP), São José do Rio Preto, São Paulo, Brasil; milena_molinari@hotmail.com; https://orcid.org/0000-0001-8558-0777

2 Universidade Estadual Paulista "Júlio de Mesquita Filho" (UNESP), São José do Rio Preto, São Paulo, Brasil; maurizio.babini@unesp.br; https://orcid.org/0000-0001-9275-726X
} 


\title{
The terminology of the cycling domain in Brazil: cases of variation among the terms that denominate the main parts of the road bike
}

\begin{abstract}
The main goal of this work is to analyze the terminology of the road cycling domain conveyed by manuals of this type of vehicle disseminated in Brazil, specifically reflecting on the variants of the terms of the main parts of the road bike found in this type of document. For that, we adopted the theoretical and methodological principles of The Communicative Theory of Terminology (CABRÉ, 1999) and also based on the criteria proposed by Faulstich $(1997,2001)$ to establish the terminological variants. Among the main results obtained, we highlight the presence of 7 cases of lexical variants and 22 geographical variants. Based on these data, we found that many manuals released in Brazil by European companies were translated into Portuguese from Portugal, which led us to find a large number of geographical variants in our analyzes, since we started with Brazilian Portuguese. With this study, we hope, then, that we can contribute to a better communication in this area, especially in the Brazilian context.
\end{abstract}

Keywords: Terminology; terminological variation; road cycling.

\section{Introdução}

Atualmente, devido à globalização e à consequente rapidez e quantidade de informações, há uma consciência maior da população com relação aos benefícios da prática esportiva (MOLINARI; CURTI-CONTESSOTO; BABINI, 2019). Além disso, as pessoas estão em busca de esportes que lhes tragam não só saúde, mas também prazer.

O ciclismo é um esporte em ascensão, pois causa uma sensação de bem-estar tanto momentâneo quanto após a sua prática, além de melhora de dores articulares, perda de peso associada a uma boa alimentação, melhoria no sono, entre tantos outros benefícios. Nesse sentido, podemos observar um grande número de ciclistas em rodovias e estradas de terra, com ciclistas visando qualidade de vida ou até mesmo uma melhor performance no esporte.

Com o aumento dos ciclistas de uma maneira geral, há uma demanda de mercado para novos modelos de bicicletas, mais modernas, mais rápidas e mais leves. Além disso, são necessárias pessoas que entendam do funcionamento das mesmas, como mecânicos de bicicleta ou bike fitters ${ }^{3}$, e também profissionais que possam auxiliar os ciclistas com

30 bike fit é o ajuste da bicicleta para o ciclista, que deve ser realizado por um profissional treinado para tal, pois ele deverá seguir alguns protocolos. Este ajuste será realizado com ajuda de um software 2D ou 3D. Este trabalho ajuda na prevenção de lesões e pode trazer maior performance e maior conforto para o ciclista durante seus treinos (Cf. TR3 Brasil, 2019). 
o treinamento, por exemplo, educadores físicos e/ou fisioterapeutas. Além da demanda por novos modelos de bicicletas e de profissionais que trabalhem com o ciclismo, há também um mercado crescente de vestuário e peças das bicicletas. Sendo assim, podemos observar um forte impacto na economia do Brasil e do mundo.

A escolha pela temática do ciclismo de estrada vem devido ao fato de esse esporte sofrer uma forte influência do campeonato francês Tour de France, a maior e mais famosa prova de ciclismo de estrada profissional do mundo. O primeiro ano do Tour de France foi em 1903 (LE TOUR, 2018), e a partir de então outras provas foram surgindo na Europa, como o Giro d'Italia em 1909 (GIRO DI ITALIA, 2018), Paris-Nice em 1933 (PARIS-NICE, 2018) e Volta da Espanha em 1935 (LA VUELTA, 2018). Esses campeonatos influenciam ciclistas e principalmente o comércio de bicicletas ao redor do mundo. Segundo Lessa e Moraes e Silva (2017), foi a partir do Tour de France que essa prática esportiva deixou de ser um esporte elitizado e passou a ser mais praticado entre atletas amadores.

É possível observar um vasto universo terminológico dentro do domínio do ciclismo, pois se trata de uma área extremamente técnica. Nesse sentido, escolhemos a Terminologia como a abordagem teórica principal de nosso trabalho, pois entendemos que ela é uma ciência interdisciplinar, ou seja, está sempre em contato com outras ciências. De acordo com Faulstich (2001, p. 12), "a Terminologia é uma disciplina que adquire matiz próprio no âmbito da interdisciplinaridade".

Para a realização deste trabalho, fundamentamos, então, nossa pesquisa na Teoria Comunicativa da Terminologia (TCT), sistematizada por Cabré (1999), e, mais especificamente, na teoria e trabalhos sobre variação terminológica de Faulstich (1997, 2001, 2002). Utilizamos como ponto de partida uma lista de termos presente no site de uma fabricante de bicicleta de estrada brasileira que considera as partes principais desse veículo. A partir dessa lista, verificamos os termos preferenciais nos manuais das bicicletas de estrada originalmente escritos em português do Brasil (PB) e em sites brasileiros especializados no domínio, glossários, base de dados, etc. Após definir o termo preferencial, fomos em busca de suas variantes, que ocorrem nos manuais originalmente escritos em PB, mas também nos manuais traduzidos para o PB e nos manuais traduzidos para o português de Portugal (PP).

Este artigo se organiza da seguinte maneira: primeiramente, apresentamos a temática de nosso estudo e as teorias nas quais nos baseamos; em seguida, discutimos a metodologia que utilizamos para a delimitação do conjunto terminológico estudado e para o estabelecimento das variantes; analisamos as variantes terminológicas, difundidas no Brasil, que denominam especificamente as partes principais da bicicleta de estrada; e finalizamos com algumas considerações e as referências utilizadas neste trabalho. 


\section{Fundamentação teórica}

A variação linguística ocorre no âmbito da língua geral e é objeto de estudo da Sociolinguística. Dentre as linhas que observam a variação nas linguagens de especialidade, temos a Socioterminologia. A Socioterminologia estuda os termos em uma perspectiva linguística, comunicativa e social. Além disso, para ela, levar em consideração o uso dos termos e os contextos nos quais eles são veiculados é de total importância: "prática terminológica é inseparável tanto do conhecimento do espaço da ação onde ela se dá, quanto das práticas de linguagem que visa modificar ou assegurar" (GAUDIN, 1993, p. 212).

Há também a Teoria Comunicativa da Terminologia - TCT (CABRÉ, 1999), que se assemelha à Socioterminologia, no sentido de que leva em consideração o uso do termo no contexto em que estão inseridos e, portanto, aceita também a variação presente nas linguagens de especialidade. Para Cabré (1999), não há como separar as variantes da comunicação especializada, mas sim analisá-las sob um ponto de vista linguístico, pragmático e cognitivo.

Partindo, então, dos pressupostos da TCT, consideramos variante como "cada uma das formas existentes de um termo" (ISO 1087, 1990, p. 6), destacando como principais tipos de variantes as ortográficas, morfológicas e sintáticas. As variantes podem seguir diferentes tipos e os critérios dessa classificação variam de acordo com a vertente teórica escolhida. No nosso caso, optamos por adotar a proposta de Faulstich (2001). Segundo Faulstich (2001, p. 22), "as variantes são resultantes dos diferentes usos que a comunidade, em sua diversidade social, linguística e geográfica, faz do termo". A figura abaixo ilustra parte do constructo teórico da variação terminológica segundo Faulstich (2001, p. 27): 
Figura 1. Constructo teórico da variação em terminologia

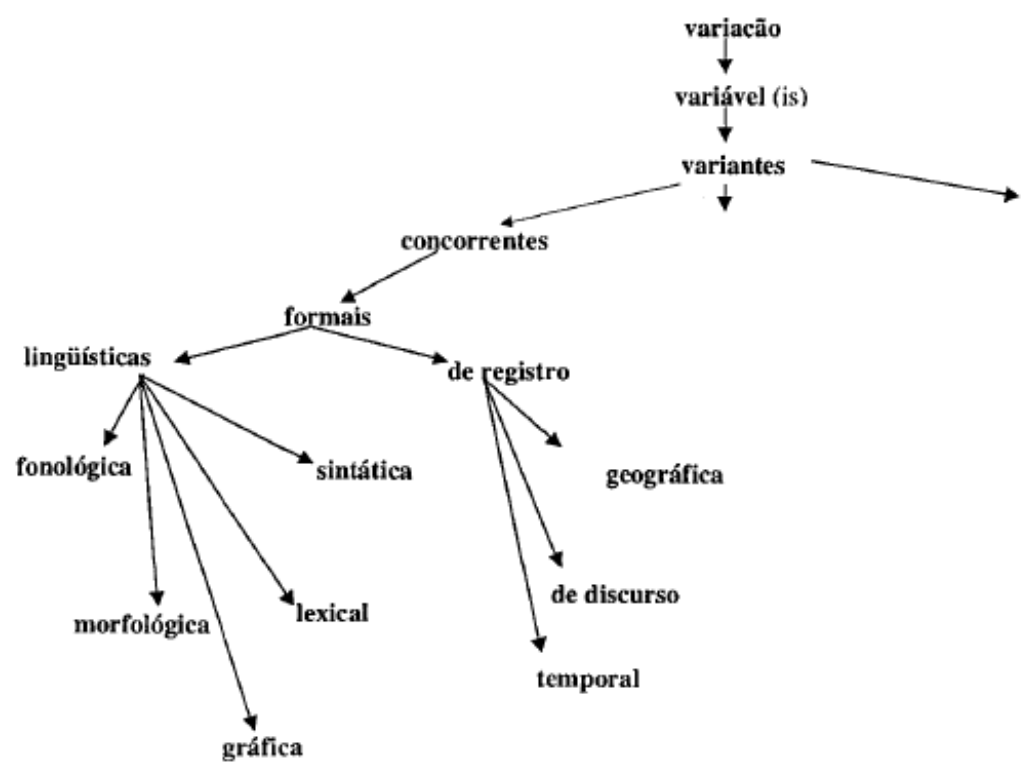

Fonte: Faulstich (2001, p. 27)

A autora divide as variantes terminológicas em duas classes:

1) Variantes terminológicas linguísticas: "são aquelas cujo fenômeno propriamente linguístico determina o processo de variação" (FAULSTICH, 2001, p. 23), podendo ser variante terminológica lexical, variante terminológica morfossintática e variante terminológica gráfica.

2) Variantes terminológicas de registro: "são aquelas cuja variação decorre do ambiente de ocorrência, no plano horizontal, no plano vertical e no plano temporal em que se realizam os usos lingüísticos" (FAULSTICH, 2001, p. 23), podendo ser variante terminológica geográfica, variante terminológica de discurso e variante terminológica temporal.

Nesse sentido, com as contribuições de Faulstich (1997, 2001, 2002), classificamos as variantes em português presentes no domínio dos termos denominativos das partes principais da bicicleta de estrada e discutimos a problemática referente a esses termos, contribuindo para o enriquecimento dos estudos em Terminologia e em variação terminológica. 


\section{Metodologia}

Este trabalho é constituído por dois corpora, sendo eles: 1) o CICLBR, composto por manuais de bicicleta de estrada em português e que foi dividido em dois subcorpora, o CICLBR-Orig (com manuais de fabricantes brasileiros) e o CICLBR-Trad (com manuais traduzidos do francês, espanhol, italiano, inglês e alemão para o português); e 2) o BIBLIOCorpusBR, que contém dicionários, livros, artigos, sites e revistas especializadas em ciclismo de estrada no Brasil.

A partir do corpus CICLBR levantamos os termos analisados neste trabalho. Assim, os manuais que o compõem foram transformados em arquivos txt com o objetivo de serem armazenados no Hyperbase (2019). Utilizamos a ferramenta Concordance, e com o auxílio da mesma adquirimos duas listas (uma referente ao CICLBR-Orig e outra, ao CICLBRTrad) com as concordâncias de todos os itens lexicais presentes nos documentos do CICLBR. A fim de ilustrar, mostramos, a seguir, um recorte da lista de concordâncias do CICLBR:

Figura 2. Lista de concordâncias do termo freio

\begin{tabular}{|c|c|c|}
\hline partie gauche & pivot & partie droite \\
\hline A DISCO por um cabo, esse tipo de & freio & apresenta boa performance de frenagem e baixa manutenção. \\
\hline Esse sistema corresponde a integração de alavanca de & freio & e trocadores de marcha, o que possibilita a \\
\hline & freio & $;$ Movimento central ; \\
\hline$u$ & freiv & Iecumendamus enctiel us prieus de d \\
\hline as alavancas de & freio & de sua bicicleta possuem o regulador de \\
\hline apertando ou soltando o regulador de a sapata de & freio & , evitando ter que \\
\hline fixados em o quadro e garfo e se 0 & freio & esta \\
\hline Para regular 0 & freio & V.Brake, \\
\hline sapatas de & freio & com uma \\
\hline de & freio & voltado para \\
\hline roteamento de os cabos de marchas e de 0 & freio & traseiro \\
\hline$\circ$ & freio & traseiro entra em 0 \\
\hline cabo de 0 & freio & traseiro sai em a parte traseira de a junção \\
\hline Cabo de & freio & traseiro Cabo de a manete esquerda \\
\hline
\end{tabular}

Fonte: Elaboração própria

Como podemos observar na Figura 2, essa lista de concordâncias apresenta os cotextos (texto ao redor) de um dos itens lexicais de nosso corpus de estudo: freio. Assim, pudemos analisar cada candidato a termo, limitando-nos aos termos denominativos das partes principais da bicicleta de estrada. Para definirmos quais eram esses termos, 
usamos como referência os termos presentes em uma lista 4 feita por um dos fabricantes brasileiros cujo manual técnico compõe o CICLBR-Orig.

Com o objetivo de facilitar o entendimento dos termos denominativos das principais partes da bicicleta de estrada, buscamos na internet uma imagem de uma bicicleta de estrada e enumeramos as suas principais partes (Figura 3). No Quadro 1, apresentamos uma legenda com os termos que denominam as partes principais da bicicleta de estrada enumerados na figura 3.

Figura 3. Principais partes que compõem a bicicleta de estrada enumeradas

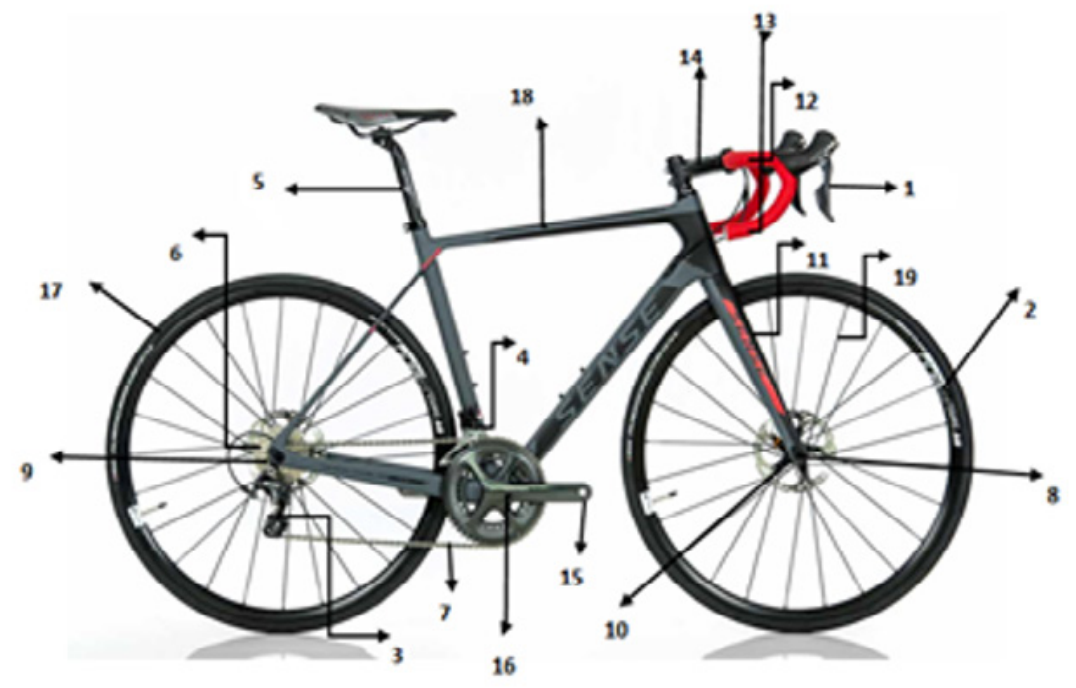

\begin{tabular}{l} 
CICLBR-Orig \\
\hline 1. alavancua de \\
câmbio e de freio \\
2. aro \\
3.câmbio traseiro \\
4. câmbio dianteiro \\
5. canote \\
6. cassete \\
7. corrente \\
8. cubo dianteiro \\
9. cubo traseiro \\
10. freio \\
11. garfo \\
12. guidão \\
13. manopla \\
14. mesa \\
15. pedal \\
16. pedivela \\
17. pneu \\
18. quadro \\
19. raio
\end{tabular}

Fonte: Sense Bikes (2019)

Em seguida, realizamos o estudo que nos permitiu encontrar as variações terminológicas em português referentes às partes principais da bicicleta de estrada. Para definir o termo preferencial, utilizamos os seguintes critérios: se encontrarmos o termo dicionarizado é um indício que ele pode ser o termo preferencial. Porém, na maior parte das vezes este determinado termo não está dicionarizado, pois não há dicionários e bases de dados específicas do domínio do ciclismo, e este fato não quer dizer que o termo com o qual estamos trabalhando não seja o preferencial. Sendo assim, usamos sites especializados

4 Lista usada como ponto de partida para definirmos as partes principais da bicicleta de estrada, que se encontra disponível em: https://www.soulcycles.com.br/bikes/3r3-ultegra-2017/. 
de fabricantes de peças e de bicicletas e glossários específicos do ciclismo encontrados na internet, material que compõe o nosso BIBLIOCorpusBR. O outro critério utilizado para definir o termo preferencial é a ocorrência daquele termo no Brasil, ou seja, aqui entendemos que os termos mais usados no Brasil são considerados termos preferenciais. Nesse sentido, as outras unidades terminológicas que denominarem o mesmo conceito foram consideradas como variantes.

\section{Análise das variações terminológicas}

Nesta seção, apresentamos as análises que dizem respeito às variantes terminológicas das principais partes da bicicleta de estrada em português. Partimos da lista apresentada na seção de metodologia que contém 19 termos originalmente escritos em português do Brasil (PB) e fomos em busca das suas variantes nos manuais traduzidos para o português. O primeiro termo apresentado é o termo alavanca de câmbio e de freio.

\section{(01) alavanca de câmbio e de freio}

Sistema indexado de troca de marchas para bicicletas de estrada, com alavancas de freio e mudança de marcha na mesma peça. Este sistema permite controle total, pois não é necessário largar o guidão ou freios para fazer as trocas. Existem modelos mais simples, com um botão de passagem na manete o outro mais acima, no corpo da empunhadura, e modelos mais sofisticados, para competição, com os dois passadores acoplados à manete de freio. (Pedaleria, 2019)

Variantes: alavanca do freio e de mudança;

manete de freio e passador de marchas;

manete de freio e trocadores de marchas;

manete de travão com manípulos;

manete de travão e manípulos de mudança;

manete do travão e manete de mudanças;

manípulos com travão e mudança;

passador de marcha com manete de freio;

trocador de marcha e alavanca de freio. 
Os termos alavanca de câmbio e de freio, alavanca do freio e de mudanças, passador de marcha com manete de freio e trocador de marcha e alavanca de freio ocorrem nos manuais do CICLBR-Orig. Devido ao fato de haver muitas variantes, definir qual seria o termo preferencial foi o maior desafio deste trabalho, pois cada fabricante das bicicletas de estrada brasileiras usa diferentes termos para o mesmo conceito, ou seja, sistema de troca de marchas para bicicletas de estrada, com alavancas de freio e mudança de marcha na mesma peça, tornando difícil a definição de qual era o termo preferencial e quais eram suas variantes. Para isso, usamos o BIBLIOCorpusBR e observamos qual era o termo mais recorrente no Brasil e concluímos que o termo alavanca de câmbio e de freio que está presente em nossa lista é o termo preferencial, sendo as outras nove opções variantes deste termo.

As opções alavanca do freio e de mudanças, passador de marcha com manete de freio e trocador de marcha e alavanca de freio são consideradas como variantes terminológicas linguísticas, mais especificadamente variantes terminológicas lexicais de alavanca de câmbio e de freio, de acordo com Faulstich (2001), pois há troca de unidades lexicais, porém essas trocas não alteram o conceito que o termo denomina.

Ao analisar os manuais do CICLBR-Trad e, em especial nesta seção, o uso dos termos manete de travão com manípulos, manete de travão e manípulos de mudança, manete do travão e manete de mudanças e manípulos com travão e mudança observamos que esses termos aparecem em manuais traduzidos para o português de Portugal (PP). Quando lemos os manuais podemos constatar com certa facilidade que não é o PB pela grafia e uso de palavras e expressões. E também constatamos que há um número maior de manuais traduzidos para o PP devido ao fato de muitas fabricantes das bicicletas serem europeias.

No que concerne ao termo manípulos com travão e mudança, este está presente no mesmo manual em que encontramos o termo manete de travão com manípulos, ou seja, observamos que dentro do mesmo manual encontramos mais de uma variante em português para este termo, mesmo se tratando de um mesmo fabricante das bicicletas de estrada.

Com relação aos termos manete de travão com manípulos, manete de travão e manípulos de mudança, manete do travão e manete de mudanças e manípulos com travão e mudança, eles são considerados como variantes terminológicas de registro, mais especificamente, variantes terminológicas geográficas do termo alavanca de câmbio e de freio, segundo Faulstich (2001, p. 29), pois elas ocorrem apenas em Portugal, ou seja, "em um plano horizontal de diferentes regiões em que se fala a mesma língua".

Já os termos manete de freio e trocadores de marchas e manete de freio e passador de marchas também se encontram no CICLBR-Trad, porém esses manuais foram traduzidos 
para o PB. O uso do termo freio já nos indica que essa é uma tradução para o PB, pois no PP há apenas o termo travão. Um dos manuais em que aparece a tradução para o PB é o manual da marca Cannondale (2019). Segundo o site Vá de bike (2013), a marca Cannondale comprou 70\% da marca brasileira Caloi. Sendo assim, acreditamos que é devido a este fato que a tradução dos manuais foi feita para o PB. O outro manual em que se destaca a tradução para o PB é o manual da marca Trek (2019), pois ao abrir o site da marca, ele já nos leva para sua versão brasileira.

Os termos manete de freio e trocadores de marchas e manete de freio e passador de marchas são considerados variantes terminológicas lexicais, de acordo com Faulstich (2001), pois assim como os primeiros termos discutidos nesta sessão, há troca de unidades lexicais, sem que haja alteração de seu conceito.

Em seguida, observamos que em nossa lista inicial há o termo aro que denomina o conceito de peça normalmente feita de alumínio, onde são colocados a câmara de ar e o pneu (Núcleo Bike, 2019). Em todos os manuais do CICLBR, o termo utilizado para denominar este conceito é o mesmo, aro, ou seja, não há variação deste termo.

Logo após, há o termo câmbio dianteiro que possui a seguinte definição:

(02)

\section{câmbio dianteiro}

Peça responsável pelas mudanças de marchas da bicicleta, com a passagem da corrente entre as coroas do pedivela. (Núcleo Bike, 2019)

Variantes: desviador dianteiro; mudança dianteira; mudança da frente.

O termo câmbio dianteiro também está presente em nossa lista inicial e para esse termo, há as variantes desviador dianteiro, mudança dianteira e mudança da frente. Essas variantes ocorrem em manuais traduzidos para o PP, enquanto câmbio dianteiro é usado como opção nos manuais traduzidos para o PB. Neste caso, observamos que o termo que está presente em nossa lista inicial é o termo usado nos manuais do CICLBR-Orig e também está presente nas traduções para o PB.

Nesse sentido, os termos desviador dianteiro, mudança dianteira e mudança da frente são considerados variantes terminológicas geográficas do termo câmbio dianteiro, pois decorrem apenas nos manuais traduzidos para o PP. Segundo Faulstich (2001, p. 29), "pode decorrer ou de polarização de comunidades linguísticas geograficamente limitadas por fatores políticos, econômicos ou culturais, ou de influência que cada região sofreu durante a sua formação.". Como estamos tratando de um outro país falante de português, é possível que essa variação aconteça devido à influência de outros países ao 
redor, especialmente na Europa onde o ciclismo de estrada é muito mais antigo do que no Brasil.

O próximo termo discutido é câmbio traseiro, com a seguinte definição:

(03)

\section{câmbio traseiro}

Peça responsável pelas mudanças de marchas da bicicleta, com a passagem da corrente entre os anéis dentados do cassete ou da catraca. (Núcleo Bike, 2019)

Variantes: desviador traseiro; mudança traseira; mudança de trás.

Com o termo câmbio traseiro o fenômeno é similar ao que acontece com o termo câmbio dianteiro, pois eles denominam o mesmo conceito, ou seja, peça responsável pela mudança de marchas, porém um é responsável pela mudança das marchas através da passagem da corrente pelas coroas do pedivela (câmbio dianteiro) e o outro pela passagem da corrente pelo cassete ou catraca (câmbio traseiro). As variantes que acontecem com o termo câmbio traseiro são desviador traseiro, mudança traseira e mudança de trás. Essas variantes também estão presentes em manuais traduzidos para o PP, ao passo que câmbio traseiro é usado como opção de tradução para o PB e para os manuais do CICLBR-Orig.

Sendo assim, como nos termos anteriormente discutidos, os termos desviador traseiro, mudança traseira, mudança de trás e câmbio traseiro são considerados variantes terminológicas geográficas do termo câmbio traseiro, segundo Faulstich (2001), pois destacam-se apenas nos manuais traduzidos para o PP.

Em seguida, apresentamos o termo canote:

(04)

\section{canote}

Se encaixa no quadro da bicicleta e fixa o selim, possibilitando a regulagem de altura do banco. (Núcleo Bike, 2019)

Variantes: canote do selim; espigão; espigão de selim; haste do selim.

Para o termo canote temos as variantes espigão, espigão de selim e haste do selim para manuais traduzidos para o PP e canote do selim para os manuais traduzidos para o PB. Também há o uso do termo canote nos manuais traduzidos para o PB e em todos os manuais que compõem o CICLBR-Orig. Os termos espigão, espigão de selim e haste do selim são considerados como variantes terminológicas geográficas do termo canote, visto que aparecem nas traduções dos manuais para o PP. Já o termo canote do selim é 
considerado como variante terminológica lexical, pois, segundo Faulstich (2001), houve um apagamento de uma parte do termo, do selim, no termo preferencial, porém sem alteração de sentido.

Com relação aos termos cassete, este denomina o conceito de "conjunto de catracas dentadas, encaixadas na roda-livre do cubo da roda traseira" (Núcleo Bike, 2019). O termo corrente indica o "conjunto de elos metálicos e flexíveis que interliga a coroa do pedivela ao cassete ou catraca da roda traseira, formando, assim, o sistema de tração da bicicleta" (Núcleo Bike, 2019). Para esses dois termos não há variação nos manuais que compõem o CICLBR, ou seja, mesmo nos manuais traduzidos são usados os mesmos termos, cassete e corrente.

Em nossa lista também estão presentes os termos cubo dianteiro e cubo traseiro. A seguir, apresentamos as suas definições.

\section{(05) cubo dianteiro}

Peça do meio da roda que é composto por um eixo com rolamentos ou esferas, possui 2 falanges metálicas onde são conectados os raios. 0 eixo do cubo é fixado no garfo através de porcas ou blocagem rápida. (Núcleo Bike, 2019)

\section{(06) cubo traseiro}

Peça do meio da roda que é composto por um eixo com rolamentos ou esferas, possui 2 falanges metálicas onde são conectados os raios. 0 cassete (conjunto de catracas dentadas) é encaixado na roda-livre do cubo da roda traseira. (Núcleo Bike, 2019)

Variantes: cubo; cubo da roda.

Os termos cubo dianteiro e cubo traseiro também decorrem nos manuais do CICLBR, porém essas duas peças possuem uma função semelhante, ou seja, ambas ficam no meio da roda e são compostas por um eixo com rolamentos onde são conectados os raios. Nesse sentido, por haver esse traço em comum entre os termos, em alguns trechos dos manuais não houve a necessidade de fazer a diferenciação entre eles e por isso ocorreram os termos cubo e cubo da roda, sem diferenciar se eram dianteiros ou traseiros, como opções de variação para cubo dianteiro e cubo traseiro. Tanto os manuais do CICLBR-Trad quanto os manuais do CICLBR-Orig usam a variante cubo e, se houver necessidade de realizar essas diferenciações, usam cubo dianteiro e/ou cubo traseiro. A opção cubo da roda apareceu em apenas um manual traduzido para o PP.

Desta maneira, o termo cubo é considerado como variante terminológica lexical dos termos cubo dianteiro e cubo traseiro, de acordo com os critérios propostos por Faulstich 
(2001), pois no caso de cubo há um apagamento de dianteiro ou traseiro, porém sem alteração de sentido. No caso de cubo da roda podemos considerá-lo como variante terminológica geográfica dos termos cubo dianteiro e cubo traseiro, pois deu-se em um manual traduzido para o PP.

Logo após, temos a defınição do termo freio:

\section{(07) freio}

São acionados por meio de cabos de aço através do acionamento da manete de freio. (Núcleo Bike, 2019)

Variante: travão

Ainda que haja um traço semântico que diferencia os termos freio traseiro e freio dianteiro, pois mesmo possuindo a mesma função, um está localizado na frente e o outro atrás da bicicleta, em nossa lista inicial apareceu somente o termo freio. A variante do termo freio é o termo travão, mesmo que no CICLBR-Trad também ocorra travão dianteiro e travão traseiro, como variação de freio dianteiro e freio traseiro. A opção travão está presente em manuais traduzidos para o PP, enquanto a opção freio nos manuais traduzidos para o PB e nos manuais do CICLBR-Orig. Desta forma, o termo travão é considerado variante terminológica geográfica do termo freio por se apresentar somente nos manuais traduzidos para o PP, de acordo com os critérios propostos por Faulstich (2001).

O próximo termo que apresentaremos é o termo garfo, que possui a definição de:

\section{(08) garfo}

Abriga a roda dianteira, se conecta com o sistema de direção da bicicleta (guidão e mesa), passando pelo quadro da bicicleta através do A-Headset. (Núcleo Bike, 2019)

Variante: forqueta

Em geral, o termo forqueta está presente nos manuais traduzidos para o PP, enquanto a opção garfo nos manuais traduzidos para o PB e nos manuais do CICLBR-Orig. É interessante notar que em um manual do CICLBR-Trad traduzido para o PP aparece o termo garfo. Em outro manual que também compõe o CICLBR-Trad traduzido para o PP verificamos a ocorrência do termo garfo e forqueta, porém neste manual há duas ocorrências para garfo e 25 ocorrências para forqueta. Sendo assim, observamos que a terminologia do domínio do ciclismo de estrada não está bem estabelecida nesses manuais. Portanto, segundo os critérios delimitados por Faulstich (2001), o termo forqueta é considerado variante terminológica geográfica do termo garfo por estar presente somente nos manuais traduzidos para o PP. 
Continuamente, discutiremos o termo guidão, que possui a seguinte definição:

\section{(09) guidão}

Peça tubular fixada na mesa destinada a orientar a direção da bicicleta. No guiador são fixados, além das manoplas, as manetes de freio e alavancas de câmbio. (Núcleo Bike, 2019)

Variante: guiador

O termo guidão decorre com mais frequência nos manuais traduzidos para o PB e nos manuais do CICLBR-Orig, enquanto guiador ocorre nos manuais traduzidos para o PP. Novamente, o termo guiador é considerado variante terminológica geográfica do termo guidão por estar presente nos manuais traduzidos para o PP, de acordo com os critérios propostos por Faulstich (2001).

A nossa próxima análise é com relação ao termo manopla, definido da seguinte maneira:

\section{(10) manopla}

Peças fixadas ao guidão destinadas a acomodar as mãos do ciclista, normalmente devem ser macias e confortáveis para evitar o cansaço ou dores nas mãos. Algumas possuem travas para dar mais estabilidade ao pedal. (Núcleo Bike, 2019)

Variante: punhos

Apesar de nossa lista inicial trazer o termo manopla como um dos principais componentes da bicicleta de estrada, tanto o termo manopla quanto o termo punhos não possuem uma grande ocorrência nos manuais, se comparados aos outros termos presentes em nossa lista. O termo manopla é opção escolhida para os manuais traduzidos para o PB e para os manuais do CICLBR-Orig e o termo punhos é a opção escolhida para os manuais traduzidos para o PP. Deste modo, segundo os parâmetros seguidos por Faulstich (2001), o termo punhos é considerado variante terminológica geográfica do termo manopla, pois ocorre em manuais traduzidos para o PP.

A seguir, apresentamos o termo mesa.

(11)

\section{mesa}

mesa ou avanço é o componente onde é afıxado o guidão, a mesa é presa à espiga do garfo (rígido ou de suspensão) através do A-headset (caixa de direção). (Núcleo Bike, 2019)

Variante: avanço 
Verifica-se o termo mesa com frequência nos manuais traduzidos para o PB e nos manuais do CICLBR-Orig. Já nos manuais traduzidos para o PP ocorre o termo avanço e em um desses manuais o termo avanço aparece com a opção mesa logo em seguida entre parênteses, mostrando para o leitor que ambos termos denominam o mesmo conceito. Nesse sentido, de acordo com Faulstich (2001), o termo avanço é considerado variante terminológica geográfica do termo mesa, pois se dá nas traduções dos manuais para o PP.

Com relação ao termo pedal que denomina o conceito de "peça fixada ao pedaleiro que é destinada a acomodar os pés do ciclista" (Núcleo Bike, 2019), não há outro termo que denomine o mesmo conceito, ou seja, o termo pedal é usado em todos os manuais que compõem o CICLBR-Trad, não havendo variações.

Por fim, analisaremos o termo pedivela, que apresenta a seguinte definição:

\section{(12) pedivela}

Duas peças conectadas ao movimento central, que possuem a função de alavanca para o acionamento dos pés. (Núcleo Bike, 2019)

Variantes: pedaleiro, pedaleira

O termo pedivela aparece nos manuais traduzidos para o PB e nos manuais do CICLBROrig e os termos pedaleiro e pedaleira nos manuais traduzidos para o PP. Observamos que, em alguns manuais, há o uso de pedaleiro e de pedaleira como sendo o mesmo termo, em alguns momentos o uso aparece no feminino e em outros momentos no masculino, não havendo uma padronização do gênero deste termo. Assim, os termos pedaleiro e pedaleira são considerados variantes terminológicas geográficas do termo pedivela, segundo os critérios propostos por Faulstich (2001), pois ocorrem nos manuais traduzidos para o PP.

No que concerne aos termos pneu, quadro e raio, não há variação para os mesmos, ou seja, em todos os manuais que compõem o CICLBR são esses os termos usados. O termo pneu denomina o conceito de "parte de borracha que tem a função de permitir o contato ao solo com aderência e atrito adequados, possibilitando assim o arranque, a frenagem e a pilotagem" (Núcleo Bike, 2019). Já o termo quadro denomina o conceito de "principal estrutura de bicicleta, é onde boa parte dos demais componentes são instalados" (Núcleo Bike, 2019). Segundo o site Núcleo Bike (2019), na região superior do quadro são fixados o selim e na inferior, câmbio dianteiro, o movimento central e a pedivela. Na frente, o garfo e na traseira, a roda, o câmbio e o freio traseiro. Atualmente, há vários materiais que podem ser usados na fabricação dos quadros, como: aço carbono, alumínio, fibra de carbono, etc. E, por fim, o termo raio denomina o conceito de "barras que unem de forma rígida, a zona central (cubo) à perimetral (aro) formando a roda da bicicleta" (Núcleo Bike, 2019). 


\section{Considerações}

Neste trabalho, objetivamos analisar as variantes terminológicas presentes no Brasil referentes às partes principais da bicicleta de estrada, segundo os critérios discutidos por Faulstich (2001). Observamos que há, no total, 7 casos de variantes terminológicas lexicais, ou seja, quando há troca de uma unidade lexical, sem alteração de sentido. Esse tipo de variação acontece com mais frequência nos manuais que compõem o CICLBROrig e CICLBR-Trad, porém apenas com os manuais traduzidos para o PB, não ocorrendo nos manuais traduzidos para o PP.

Ademais, o tipo de variante terminológica que mais se destaca neste artigo são as variantes terminológicas geográficas, que ocorrem, sobretudo, nos manuais do CICLBRTrad traduzidos para o PP. Há, no total, 22 variantes terminológicas geográficas.

Há muito mais fabricantes das bicicletas de estrada estrangeiras do que brasileiras e, por isso, os manuais do CICLBR-Trad são mais numerosos do que os manuais do CICLBROrig. Outro fator que devemos levar em consideração é que a maioria das fabricantes das bicicletas de estrada são europeias, pois o ciclismo de estrada se popularizou com o Tour de France, conforme mencionamos. Sendo assim, há uma predominância dos manuais traduzidos para o PP, do que os traduzidos para o PB. Isso explica o fato de haver muito mais variantes geográficas em nosso corpus do que variantes lexicais.

É interessante observar que os termos aro, cassete, corrente, pneu, quadro e raio não têm variantes, ou seja, esses são os termos usados em todos os manuais que compõem o CICLBR.

A terminologia do domínio do ciclismo de estrada é extremamente técnica e de difícil entendimento e, além disso, é um domínio muito amplo e pouco explorado. Observamos, ainda, que há um problema de comunicação especializada nesse domínio, motivado pelos manuais, uma vez que as empresas europeias usam a tradução do PP para divulgar os produtos no Brasil, causando uma confusão terminológica para os especialistas, e, principalmente, para os consumidores desses veículos. Sendo assim, esse estudo busca melhorar a comunicação da área em pauta, mostrando quais são os termos do PB e quais são os termos do PP. Em razão disso, acreditamos que nosso trabalho visa contribuir para os estudos em Terminologia, especialmente no campo da variação terminológica no Brasil.

Por fim, buscamos também ajudar profissionais da área e atletas, pois é importante entender o conceito que cada termo denomina e as variações dos mesmos, já que pedalar de forma segura vai muito além de subir na bicicleta e sair pedalando; consiste em saber técnicas de ciclismo e em comprar o equipamento correto para as necessidades de cada ciclista, proporcionando, assim, um bom uso de sua bicicleta. 


\section{Referências}

CABRÉ, M. T. La Terminología: representación y comunicación. Elementos para una teoría de base comunicativa y otros artículos. Barcelona: IULA, 1999.

CANNONDALE. Cannondale. Disponível em: https://www.cannondale.com/en/ International. Acesso em: 9 jul. 2019.

FAULSTICH, E. Aspectos de terminologia geral e terminologia variacionista. Tradterm, v. 7, p. 11-40, 18 dez. 2001. Disponível em: http://www.revistas.usp.br/tradterm/article/ view/49140/53222. Acesso em: 24 ago. 2018.

FAULSTICH, E. Entre a sincronia e a diacronia: variação terminológica no código e na língua. In: CORREIA, M. (org.). Terminologia, desenvo/vimento e identidade nacional. Lisboa: Colibri/ILTEC, 2002. p. 61-74.

FAULSTICH, E. Variação terminológica: algumas tendências no português do Brasil. In: Cicle de conferències 96-97: lèxic, corpus i diccionaris. Barcelona: IULA, 1997.

GAUDIN, F. Pour une socioterminologie: des problèmes sémantiques aux pratiques institutionnelles. Rouen: Université de Rouen, 1993. (Coleção « Publications de I'Université de Rouen », 182).

GIRODITALIA. Giro archieve: previous editions. Disponível em: http://www.giroditalia.it/ eng/editions/. Acesso em: 19 mar. 2018.

HYPERBASE. Hyperbase Web edition. Unice: Université Côte d'Azur. Disponível em: http://hyperbase.unice.fr/hyperbase/. Acesso em: 20 mar. 2019.

LAVUELTA. Grandes momentos en la historia de la Vuelta. Disponível em: http://historia. lavuelta.com/. Acesso em: 19 mar. 2018.

LESSA, P. R.; MORAES E SILVA, M. O ciclismo de estrada e a construção de uma cultura nacionalista: um olhar sobre o Tour de France. Movimento (ESEFID/UFRGS), Porto Alegre, p. 407-418, mar. 2017. Disponível em: http://www.seer.ufrgs.br/index.php/Movimento/ article/view/64603. Acesso em: 18 mar. 2018.

LETOUR. L'histoire du Tour de France. Disponível em: https://www.letour.fr/fr/histoire. Acesso em: 19 mar. 2018. 
MOLINARI, M. P.; CURTI-CONTESSOTO, B.; BABINI, M. Um estudo dos graus de equivalência entre os termos denominativos das partes principais da bicicleta de estrada no Brasil e na França. Revista da Abralin, v. 18, n. 1, p. 1-34, 2019. Disponível em: http://revista.abralin.org/index.php/abralin/article/view/1359. Acesso em: 07 maio 2020. DOI: 10.25189/RABRALIN.V18I1.1359

NÚCLEO BIKE. Conhecendo as peças de uma bicicleta. Disponível em: http://www. nucleobike.com.br/dicas/conhecendo-as-pecas-de-uma-bicicleta/. Acesso em: 28 fev. 2019.

ORGANISATION INTERNATIONALE DE NORMALISATION. Terminologie - Vocabulaire. Genebra. ISO, 1990 (Norme Internationale ISO 1087, 1990).

PARIS-NICE. Histoire de Paris-Nice. Disponível em: https://www.paris-nice.fr/fr/histoire. Acesso em: 19 mar. 2018.

PEDALERIA. Tipos de alavancas de câmbio. Disponível em: http://www.pedaleria.com. br/alavancas-de-cambio/. Acesso em: 19 abr. 2019.

SENSE BIKES. Road, tri, gravel. Disponível em: https://sensebike.com.br/bikes/road-trigravel/. Acesso em: 5 ago. 2019.

TR3 BRASIL. Bike Fit 2D dinâmico. Disponível em: https://www.tr3brasil.com.br/blog/ bike-fit-2d-dinamico. Acesso em: 4 jun. 2019.

TREK. Trek. Disponível em: https://www.trekbikes.com/br/pt_BR/countries/. Acesso em: 9 jul. 2019.

VÁ DE BIKE. Cannondale compra 70\% da brasileira Caloi. Disponível em: http://vadebike. org/2013/08/cannondale-adquire-caloi-fabricante-bicicletas/. Acesso em: 9 jul. 2019. 